\title{
First Salmon Ceremony in the Southernmost Area of Salmon Habitat
}

\author{
Kenji Yoshimura ${ }^{1}$ and Ryusuke Kodani ${ }^{2}$ \\ ${ }^{1}$ International Coastal Research Center, Atmosphere and Ocean Research Institute, The University of Tokyo, \\ Akahama 1-19-8, Otsuchi-cho, Iwate 028-1102, Japan \\ ${ }^{2}$ Nara National Research Institute for Cultural Properties, Nijocho, 2-9-1, Nara-shi, Nara 630-8577, Japan
}

Keywords: first salmon ceremony, culture of salmon, importance of salmon in communities

Salmon inhabit the North Pacific Ocean and are an extremely important food source for people who live around the North Pacific rim. Salmon are not only important to people as a food resource there, but the capture and utilization are very important culturally. The first salmon ceremony is an important cultural event that takes place around the southernmost area of salmon habitat.

Gunther's research $(1926,1928)$ on salmon rituals in the North Pacific region, especially on the American continental side, hardly touches on the Japanese archipelago and the Far East, including Hokkaido. By comparing the beliefs and customs of the Ainu, the people of northern Honshu, the indigenous people of the Amur River basin, and the indigenous people of Sakhalin in relation to salmon hunting, Obayashi proposes that the salmon rituals from Amurland through Hokkaido to northern Honshu be viewed as a single continuum (Obayashi 1992, 1996). In addition, Suga (2000) and Suzuki (2004), among others, have conducted research on salmon rituals around the Tohoku region.

The objective of this study is to understand the status of salmon culture in the southern limit of salmon habitat. The target of the research is the MATABE ceremony, the first salmon ceremony in the Tsugaruishi district of Miyako City, Iwate Prefecture. We surveyed rituals related to the MATABE ceremony. The research was conducted by participating in the ritual, interviewing the people involved, and collecting historical data.

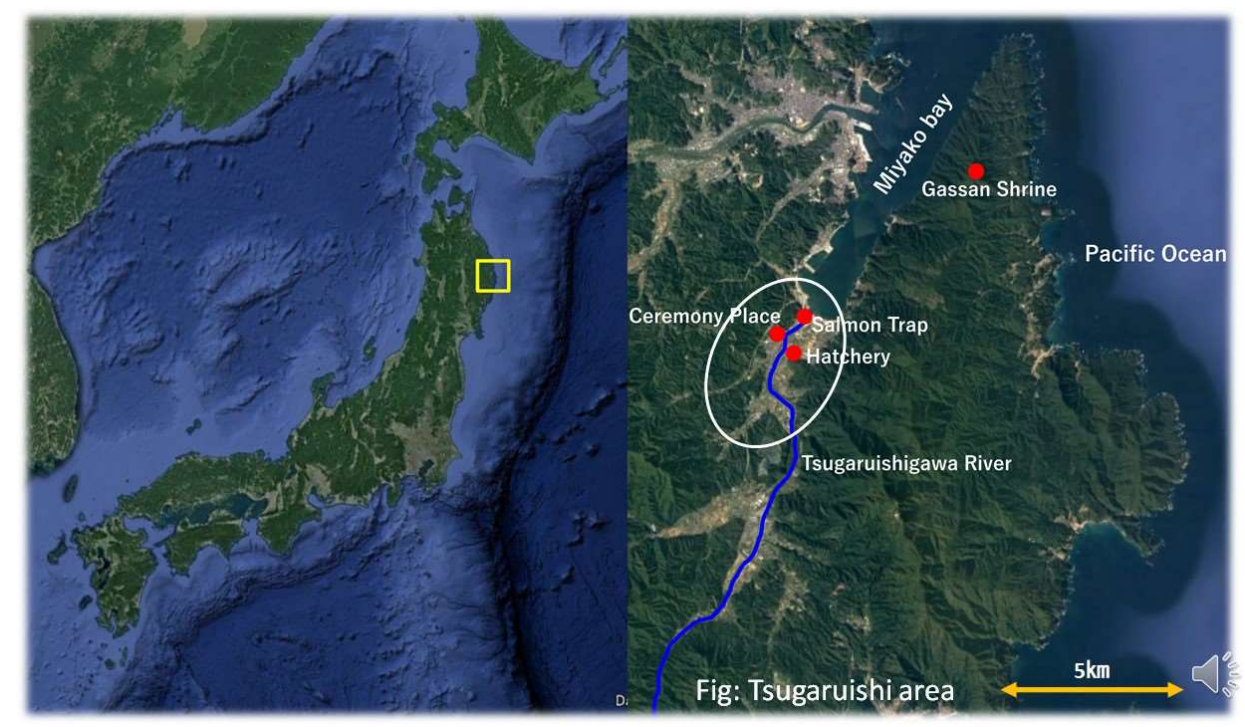

Fig. 1. Tsugarushi area.

In this paper, the case study of the ceremony is the Tsugaruishi area, Iwate prefecture (Fig. 1). Tsugaruishi is one of the rivers with the highest salmon catch in the Tohoku region. The first salmon ceremony at Tsugaruishi, called MATABE ceremony, is one of the most distinctive and rare salmon ceremonies in Japan. In addition to the first salmon ritual, Tsugaruishi has various traditions and myths related to salmon.

Artificial hatching of salmon is also carried out in Tsugaruishi River, but the system is slightly different from others. In Japan, fishery cooperatives generally handle everything from salmon capture to artificial hatching. However, in Tsugaruishi, artificial hatching is carried out by fishery cooperatives while salmon capture is carried out by specialized organizations. The caught salmon are fertilized on the spot by the fishery cooperative's staff. The used salmon is sold to general customers at the shop managed by the capture organization and the profits are used for operating expenses of the organization. Salmon capture organizations in Tsugaruishi have played a very important role in the management of local communities. For example, the cost of public activities in the district was 
paid by the capture organization, and salmon was distributed to the district members of Tsugaruishi. After the earthquake in 2011, they handed relief money to residents. In this way, salmon play a very important economic role in Tsugaruishi.

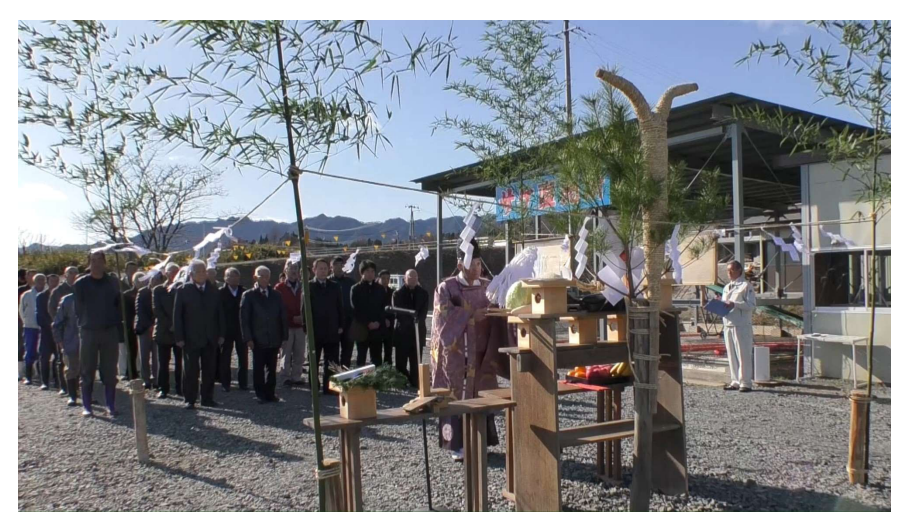

Fig. 2. MATABE ceremony.

The "MATABE ceremony" is held at noon on 30 November every year. The ceremony is performed by a salmon capture organization and is attended by those concerned with the district at Tsugaruishi. The feature of this ceremony is to use a bifurcated straw doll named "MATABE" (Fig. 2). An old tradition in Tsugaruishi has it that a man named MATABE once broke a salmon net to save people from starvation, but that action of breaking the salmon net was a serious crime at that time and he was executed upside down. After the death of MATABE, salmon no longer ran up the river. The villagers considered it the curse of MATABE and mourned him. After mourning, the salmon started to run up the river again. Since then, people have performed this ritual at Tsugaruishi to mourn MATABE and pray for a good catch of salmon. It is from this narrative that the people of Tsugaruishi worship MATABE as a hero and now perform this ceremony. The shape of the doll imitates MATABE being killed upside down. The use of a straw doll for salmon rituals is very characteristic of this region and this is the only place in Japan where straw dolls are used in salmon rituals. Finally, during the ceremony the representative sprinkles water drawn from the Tsugaruishi river on the MATABE doll (Fig. 3). I explained that straw dolls imitate the shape of a person, but there is also a theory that they imitate the shape of a fish because the act of pouring water from the river reminds people of salmon. We will omit it here, but there are other factors that are reminiscent of salmon from the form of the old ritual. The ceremony finishes after this performance and the dolls are stored on the riverside until around February, when the salmon fishing season on the river ends.

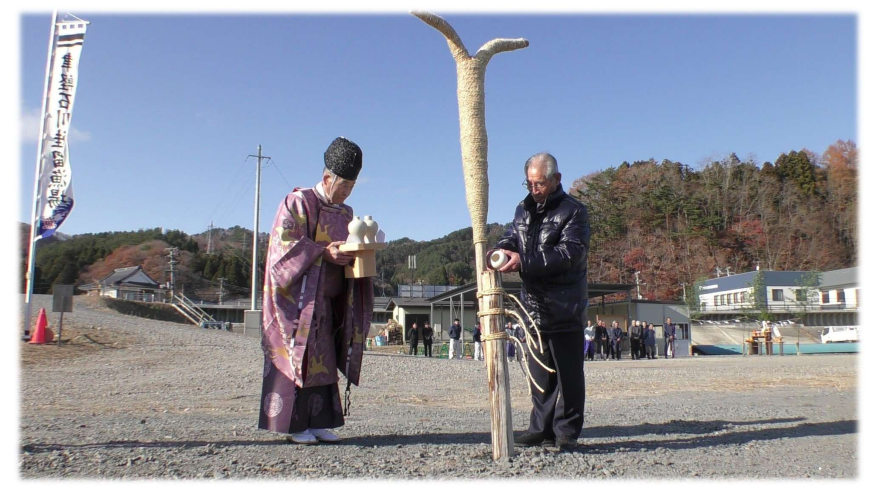

Fig. 3. Sprinkles the water drawn from the Tsugaruishi river on the MATABE doll.

The first salmon ceremony is one of the ceremonies that pray for a big salmon catch. A ceremony marking the event of the first salmon run of the season is practiced by many coastal Native groups on the North Pacific Coast (Gunther 1926, 1928) and many of the ceremonial features are similar throughout the area. Many tribes on the coast make salmon one of their principal foods. In most localities there are no salmon in streams during some seasons, or if any are to be found the quality is so poor that Natives do not use them. Hence the coming of the first salmon is a real event, for it means not only a change from a diet of dried meats and fish, but in many instances saves people from imminent starvation. The first salmon ceremony tends to take place in the southern area of salmon habitat. The commonalities between salmon ceremonies in northern Japan and the Northwest Coast have often been pointed out (Obayashi 1992). Finally, we consider why the first salmon ceremony remains around the southernmost area of salmon habitat. 
When considering the factors behind these remaining first salmon ceremonies in the southern area of salmon habitat, we need to consider the position of salmon at a local level. So, we would like to point out the following three points: the monetization of salmon, timing of salmon run-up, and food importance of salmon.

(1) Monetization of salmon: As we mentioned earlier, when looking at the salmon hatching systems of Tsugaruishi, the economic contribution of salmon cannot be overlooked. The sales of salmon caught in the river are often used for the operation of the Tsugaruishi community. In other words, it is an area where salmon is indispensable for the operation of the local community. It has a history of at least 100 years and this operation system is still in place now.

(2) The timing of salmon run-up: Although it is related to the next point, the timing of salmon run-up is the off-season agricultural work that makes it possible to devote a lot of labor to fishing and securing food (Kodani 2002).

(3) Food importance of salmon: Since salmon migrate upstream from autumn to winter, they have been regarded as a valuable source of nutrition in winter. Salmon is a fish that is said to have no parts to throw away, has high nutritional value, and above all is a highly conserved food - an example being Aramakisake (dried salmon with salt; Fig. 4). Traditionally, a Japanese diet has depended on rice, and there is a proverb around northern Japan that states salmon can be captured in large numbers in a year when rice is poor. Therefore, some people value salmon as much as rice.

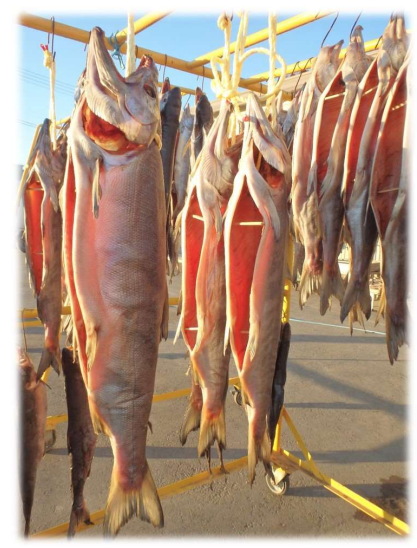

Fig. 4. Aramakisake (dried, salted salmon).

Note-First salmon ceremonies can be universally confirmed in northern Japan, where salmon rituals are widely practiced. Due to present difficulties, I cannot provide an in-depth look at the cultural role of salmon in North America, however it should be pointed out that salmon have a special meaning to several North American tribes. Eventually, this point needs to be considered in comparison with other rituals.

\section{REFERENCES}

Gunther, E. 1926. An analysis of the First Salmon Ceremony. Am. Anthropot. 28(4): 605-617.

Gunther, E. 1928. A further analysis of the First Salmon Ceremony. Univ. of Washington Publications in Anthropology 2: 129-173.

Kodani, R. 2002. Farmer and salmon fishing. Tohoku Minzoku (Folklore of Tohoku) 36: 1-7. (In Japanese)

Obayashi, T. 1992. Salmon in North Pacific myths and rituals. Bulletin of the Hokkaido Museum of Northern Peoples 1: 1-16. (In Japanese)

Obayashi, T. 1996. Salmon in myth and ritual in the Northern Pacific area. In Shamanism and Northern Ecology Edited by Juha Pentikainen. pp. 313-329.

Suga, Y. 2000. Folk history created by Shugen (Buddhist priest). Yoshikawa kobunkan, Tokyo.

Suzuki, M. 2004. The orthodoxy of ritual tradition: A case of Miyako City in Iwate prefecture. Journal of Law, Politics, and Sociology 77(1): 185-235. (In Japanese) 